\title{
Why Kindergarten is the Model English Learner Educational Environment
}

\author{
Deborah L. Wheeler ${ }^{1}$
}

Published online: 17 March 2020

(c) Springer Nature B.V. 2020

\begin{abstract}
Kindergarten classrooms present a wide range of support for students, and when teaching English learners' (EL), support is vital to everyone's learning. Therefore, similar to a kindergarten classroom, K-12 classrooms should offer a language rich classroom setting that is geared towards assisting and supporting students that are learning English as a second language. The K-12 teacher is expected to facilitate and promote language learning through the application of specific multilingual strategies and to provide an accepting multilingual and multicultural educational environment. Teachers who have not taught kindergarten may not be familiar with the educational methods utilized in this classroom environment and may not be able to connect this methodology to first through twelfth grade classroom settings; however, by observing an exceptional multilingual and multicultural kindergarten classroom all teachers will be able to comprehend how this is conducive to teaching ELs in all grades.
\end{abstract}

Keywords English learner $\cdot$ Multilingual $\cdot$ Multicultural $\cdot$ Early childhood

When walking into an effective kindergarten classroom you will enter a warm, welcoming learning environment with academic visuals on the walls, work produced by the students displayed, labels placed throughout the room, with manipulatives, blocks, reading material, an easel and practical and relevant real-world items such as a kitchen, and so much more. Often, the teacher is enthusiastically greeting students with a hug to make them feel welcome; the teacher demonstrates that she is caring and conscientious of the students' emotional, physical, and intellectual needs. Similarly, the teacher truly understands what is developmentally appropriate. According to the U.S. Departments of Health and Human Services (HHS) and Education (ED), “...early childhood programs adequately and appropriately serve the diverse children and families that make up this country. Programs should foster their cognitive, linguistic, social emotional, and physical development and prepare them for success in school and beyond" (2017).

Deborah L. Wheeler

dwheeler@stcloudstate.edu

1 Department of Child \& Family Studies, St. Cloud State University, B129 Education Building, 720 4th Ave S, St. Cloud, MN 56301-4498, USA
In high quality early education environments, each student feels connected in the educational experience and the closeness that is present in the classroom reflects a family atmosphere. The teacher speaks with clarity and expression to make sure that the students understands. Furthermore, the teacher uses gestures, provides visuals, and realia to assist with comprehensible instruction. These are the teaching practices that should be adopted by all teachers in the kindergarten through twelfth grade classroom. Further methodology employed by the kindergarten teacher demonstrates additional best practices and research-based teaching strategies that are effective when teaching all students.

Observing the kindergarten teacher in action demonstrates the intense energy that must be expended in order to build knowledge and expand schema. A plethora of materials are used when teaching and these include visuals, manipulatives, realia, technology, and hands-on experiences to enable students to be actively engaged and involved in learning. Centers are prevalent and the pedagogy is student-centered as well as differentiated. Certainly, teaching to multiple modalities is an integral part of the lessons, along with comprehension checks, repetition, and practice. In addition, theme-based instruction allows the students to see the connection between each of the content areas and enables the 
students to become familiar with the interrelationship of all levels of learning.

In the kindergarten classroom, one observes students spread out throughout the classroom and at times they are sprawled across the floor, working cooperatively on an assignment. Students are involved in learning and are utilizing listening, speaking, reading, and writing skills. The teacher, who is knowledgeable about the needs of learners, supports the entire academic process and creates a learning environment that allows students' educational experiences to be meaningful and relevant. As a result, students are challenged and motivated to learn. The students remain interested because the teacher incorporates music, art, cooking, technology, movement, and educational games and activities that touch upon the students' senses. Likewise, students enjoy reading because the reading center has a variety of books with diverse genres from which to choose. Reading is supported and encouraged through a comfortable environment because students read in the playhouse or in a beanbag chair. Accordingly, the teacher knows that exposure to reading materials and providing opportunities to read will assist in inspiring most students to want to read, learn to read, and continue to have a desire to read throughout their lives.

Moreover, the teacher is cognizant that Maslow's Hierarchy of Needs must be met in order for the students to be successful; thus, the teacher ensures a positive learning environment where students are encouraged to participate without fear of criticism or humiliation. The National Association for the Education of Young Children (NAEYC) recommends in the 2019 Advancing Equity in Early Childhood, “...create early learning environments that equitably distribute learning opportunities by helping all children experience responsive interactions that nurture their full range of social, emotional, cognitive, physical, and linguistic abilities; that reflect and model fundamental principles of fairness and justice; and that help them accomplish the goals of antibias education" (NAEYC 2019). In kindergarten, students typically demonstrate an eagerness to learn and enthusiasm to gain social interaction and skills. Accordingly, the curriculum should be free from bias, with an emphasis on the joy of diversity and an obvious focus on language and multiculturalism. Undoubtedly, the core standards are met while students are actively engaged in learning and, in fact, learning is seen as fun.

Indeed, many states have adopted the Common Core State Standards, which can be challenging for both teaching and learning. However, effective teachers are still implementing sound pedagogy that takes into account the needs of individual students, and the demographics of the school. Effective teachers remain strong in their conviction to teach utilizing student-centered best practices.

\section{Beyond Kindergarten}

The aforementioned researched-based ESOL strategies should be practiced in kindergarten through twelfth grade classrooms. This is not to say that teachers in upper grades must reduce the knowledge base or level of learning to a kindergarten level; instead, embedding a high-quality curriculum that is language-rich and differentiated with supportive multilingual and multicultural strategies similar to a nurturing and enriching kindergarten classroom is effective for all learners at all grade levels. Emulating like kindergarten teachers, teachers delivering instruction in a way that utilizes strategies and instructional methodology such as modeling, listening, guided instruction, discovery, explicit instruction, cooperative learning, and independent practice will support and promote success (Dove and Honigsfeld 2013). Indeed, effective teachers help to meet the instructional needs of individual students by scaffolding and meeting diverse needs.

What K-12 teachers should be providing to students is a student-centered teaching curriculum in a classroom that is academic, positive, and diverse. The teacher creates a classroom where students treat each other as family and where students find that applying themselves, being responsible, working hard, and taking ownership of their learning is valued. Consequently, students will strive to achieve success and the teacher will be aware of individual needs. The educational experience and curriculum is designed in a way that satisfies students' diverse needs, language abilities, cultural backgrounds, and learning styles. Brassell and Rasinski (2011) confirmed, "By allowing students to develop an array of products to showcase their growth and understanding, teachers can accommodate the diverse abilities present in their classrooms" ( $p$. 23).

Differentiated instruction does not require the teacher to deviate from academic standards. Rather, the academic standards and expectations remain the same, but the lessons that include the standards are arranged to suit the learner. After choosing the standards to be formulated within the lesson, the teacher should creatively devise multiple teaching methods that will motivate students and enable them to attentively demonstrate the standards they have learned (Bassell and Rasinski 2011). Subsequently, students learn the concepts in a meaningful way that enables the information to be stored in their longterm memory, thus establishing applicable and retrievable knowledge.

Remembering information that is relevant and meaningful is easier students are involved in what they are doing. Accordingly, field trips, cooperative learning experiences, science experiments, and projects are easy to recall 
because these learning experiences are entertaining, meaningful, applicable, and academic in their approach. Similarly, the educational experiences for students in the K-12 classroom should be the same. Success is eminent when the learner values the experience.

\section{English Learners}

In today's multicultural classroom, the research based multilingual strategies and methodology that encompass multicultural education are the most effective means of providing comprehensible instruction for English learners (ELs). Students from diverse cultural groups with a language other than English must be taught using effective instruction that focuses on educational elements beyond just teaching the English language (Banks 2006). By offering differentiated instruction to meet individual needs and by encouraging cooperative learning or other interactive strategies in a positive and non-threatening learning environment, all teachers will discover that ELs will be able to be engaged in the learning process.

Moreover, like a kindergarten classroom, focusing on providing comprehensible instruction with appropriate strategies and modifications will enable ELs to learn the concepts, while at the same time acquiring the English language. Offering modified homework, classwork, and assessments that assess if ELs have learned the concepts of the lesson will guide every teacher and all students towards identifying strengths and weaknesses that should be revisited, re-taught, or expanded. It is pivotal that every teacher, across all grade levels, acquire knowledge about ELs' cultural background, as well as their educational experiences, and linguistic abilities in order to ensure that expectations align with every student's experience.

Jong and Harper (2008) confirm, “...good teachers make their instruction more accessible through the use of graphic organizers, cooperative learning, hands-on activities, and attention to specialized content-specific vocabulary" (p. 128). Furthermore, choosing appropriate strategies and modifying homework, classwork, and assessments to meet ELs' proficiency levels is essential. Involving ELs in learning activities and encouraging all students to accept diversity and support for each other will positively impact the classroom and the self-esteem of ELs. Additionally, the ELs will be able to discover that they are accepted, engaged, and on the road to becoming successful learners.

In the kindergarten classroom, centers are a part of daily exploratory activities. Similarly, centers are one way to allow ELs to explore and discover a variety of topics in multiple ways. Not only do centers create individualized learning, but they also provide opportunities for collaborative work. In addition, centers are non-threatening and relaxed so that
ELs may actively engage in problem-based learning experiences. ELs will comprehend the concepts through the varied content-based activities in the centers. Typically, ample time must be given to explore learning. While students are engaged in the centers, the teacher is able to maneuver around the room assisting students and monitoring learning gains and scaffolding the inquiry process.

Providing ELs with graphic organizers, sensory supports, and visual aids will enable them to apply their prior knowledge. Implementing multimedia, songs, and dance will create an engaging learning opportunity. Indeed, creative teaching requires that the teacher differentiates instruction and addresses the needs of the whole student. In other words, a holistic approach will enable the teacher to address the educational needs of ELs taking into account their culture, proficiency levels, background knowledge, motivation, and interests. By being aware of this critical information, the teacher is better able to meet the needs of ELs. Additionally, these insights will assist in relating, connecting, and motivating ELs in the classroom.

Since the English language is embedded in every content area, the teacher must make specific modifications and utilize essential multilingual strategies in order to provide comprehensible instruction. The teacher must choose the best methodology in order to ensure that ELs are provided equal educational opportunities. Certainly, strategies and modifications that are an integral part of the kindergarten classroom are effective in all classrooms, provided the teacher maintains an age-appropriate curriculum.

Overall, the teacher chooses the strategies and modifications that are suitable for ELs and designs engaging and interesting classroom instruction. Like a kindergarten teacher, the first through twelfth grade classroom teacher must be able to create lessons that are challenging, language enriched, and student-centered. Peregoy and Boyle (2005) postulate that challenging students while at the same time providing scaffolding will invariably assist with academic development and English proficiency. Undoubtedly, teaching content through memorable learning experiences to ingrain knowledge in long-term memory that can be recalled at any given moment and applied to the real world, illustrates successful quality educational practices. Indeed, the K-12 classroom teacher is responsible for providing meaningful academic experiences for all learners and with the increase in diversity in the classroom today, teachers must be able to develop effective and meaningful educational experiences that reflect the holistic approach of a kindergarten classroom.

Perhaps, what has been described may appear to be the ideal classroom setting, but it is achievable and in practice in many schools. Regardless of the grade level, teachers must strive to put into practice the ideal teaching practices, which are research-based strategies and best practices. Even with the challenges of Common Core State Standards, if these 
sound teaching methodologies are not implemented, student achievement may be mediocre at best. In sum, the ideal classroom contains a teacher who does his or her best to put into practice these researched-based strategies. Success in teaching is what all educators should aspire to achieve, and educational success is what all educators should foster in their students by providing them with the tools and strategies to achieve and succeed.

\section{References}

Banks, J. A. (2006). Cultural diversity and education: Foundations, curriculum, and teaching (5th ed.). Boston, MA: Pearson Education Inc.

Brassell, D., \& Rasinski, T. (2011). Comprehension that works: Taking students beyond ordinary understanding to deep comprehension. Huntington Beach, CA: Shell Education.

de Jong, E. J., \& Harper, C. A. (2008). ESL is good teaching "plus": Preparing standard curriculum teachers for all learners. In M. E. Brisk (Ed.), Language, culture, and community in teacher education (pp. 127-148). New York, NY: Lawrence Erlbaum
Associates/Taylor \& Francis Group for the American Association of Colleges for Teacher Education.

Dove, M. G., \& Honigsfeld, A. (2013). Common Core for the notso-common learner: English language arts strategies grades $k-5$. Thousand Oaks, CA: Corwin.

National Association for the Education of Young Children. (April, 2019). Advancing equity in early childhood education (Position Statement). Retrieved from https://www.naeyc.org/sites/default/ files/globally-shared/downloads/PDFs/resources/position-state ments/naeycadvancingequitypositionstatement.pdf.

Peregoy, S. F., \& Boyle, O. F. (2005). Reading, writing, and learning in ESL: A resource for $K-12$ teachers (4th ed.). Boston, MA: Pearson Education Inc.

U.S. Department of Health and Human Services, U.S. Department of Education. (2017). Policy statement on supporting the development of children who are dual language learners in early childhood programs. Retrieved from https://www.acf.hhs.gov/sites/ default/files/ecd/dll_policy_statement_final.pdf.

Publisher's Note Springer Nature remains neutral with regard to jurisdictional claims in published maps and institutional affiliations. 